\title{
Efektivitas Komunikasi Dakwah Kelas Jodoh terhadap Perubahan Wawasan Member Kelas Jodoh untuk Membangun Keluarga Sakinah di Bandung
}

\author{
Salshabilla Firdausi", Nia Kurniati Syam \\ Prodi Komunikasi dan Penyiaran Islam, Fakultas Dakwah, Universitas Islam \\ Bandung, Indonesia. \\ *salshabillafierdausi@gmail.com,nia_syamday@yahoo.com
}

\begin{abstract}
Marriage is one of the worship that is ordered in the teachings of Islam. One of the efforts to optimally achieve God's commandments is to follow the program. Matchmaking class, 'Kelas Jodoh' is a prewedding class activity program that provides solutions to build a sakinah family according to Islamic law, a forum to unite people who have the same vision, who want to improve themselves to be able to get the best mate and build a sakinah, mawaddah, warrahmah family. The purpose of this study was to determine the program carried out in Kelas Jodoh, to understand the communication methods of Da'wah in Kelas Jodoh activities carried out by Ustadz Setia Furqon Kholid, and to find out the extent to which the effectiveness of the Da'wah Communications in Kelas Jodoh was to the insight of members of Kelas Jodoh to build a sakinah family. This type of research uses descriptive quantitative methods. With a sample of 76 members of the Match Class from a total population of 320 members of Kelas Jodoh in Bandung. Data collection techniques in the form of observation, distributing questionnaires, interviews and literature study. This study uses data analysis techniques in the form of validity test, normality test, reliability test, linearity test, simple linear regression test, $\mathrm{f}$ test, coefficient of determination test. From the results of the study, it was found that $73 \%$ of the influence of Kelas Jodoh activities on changes in the insights of Kelas Jodoh members in building a sakinah family.
\end{abstract}

Keywords: Effectiveness, Da'wah Communication, Matchmaking Class, Sakinah Family.

\begin{abstract}
Abstrak. Pernikahan merupakan salah satu ibadah yang diperintahkan dalam ajaran agama Islam. Salah satu upaya pencapaian perintah Allah dengan optimal adalah mengikuti program. Kelas Jodoh merupakan program kegiatan kelas pra-nikah memberikan solusi untuk membangun keluarga yang sakinah sesuai syariat Islam, wadah untuk menyatukan orang-orang yang mempunyai visi yang sama, yang mau memperbaiki diri untuk bisa mendapatkan jodoh terbaik dan membangun keluarga sakinah, mawaddah, warrahmah. Tujuan penelitian ini adalah untuk mengetahui program yang dilakukan dalam Kelas Jodoh, memahami metode komunikasi dakwah pada kegiatan Kelas Jodoh yang dilakukan oleh Ustadz Setia Furqon Kholid, dan mengetahui sejauh mana efektivitas komunikasi dakwah Kelas Jodoh terhadap wawasan member Kelas Jodoh membangun keluarga sakinah. Jenis penelitian ini menggunakan metode kuantitatif deksriptif. Dengan sampel 76 member Kelas Jodoh dari total populasi 320 member Kelas Jodoh wilayah Bandung. Teknik pengumpulan data berupa observasi, penyebaran kuesioner, wawancara dan studi kepustakaan. Penelitian ini menggunakan teknik analisa data yang berupa uji validitas, uji normalitas, uji realibiltas,uji linieritas, uji regresi linear sederhana, uji f, uji koefisien determinasi. Dari hasil penelitian, ditemukan sebesar $73 \%$ adanya pengaruh kegiatan Kelas Jodoh terhadap perubahan wawasan member Kelas Jodoh dalam membangun keluarga sakinah.
\end{abstract}

Kata Kunci: Efektivitas, Komunikasi Dakwah, Kelas Jodoh, Keluarga Sakinah. 


\section{A. Pendahuluan}

\section{Latar Belakang}

Jumlah perceraian di Indonesia menunjukkan tren peningkatan. Data terakhir hasil perhitungan Kementerian Agama RI mencatat terjadinya 250 ribu kasus perceraian di Indonesia pada tahun 2009 sebanyak 2,5 juta. Jumlah perceraian tersebut naik 50 ribu kasus dibanding tahun 2008 yang mencapai 200 ribu perceraian.

Perceraian di Indonesia dapat dikabulkan oleh pengadilan dengan ketentuan karena adanya penganiayaan baik fisik maupun psikis, adanya cacat biologis, hukuman yang diterima oleh salah satu pihak, adanya ketidakharmonisan rumah tangga, adanya perbuatan amoral seperti perzinahan, mabuk, madat, judi, karena kepergian salah satu pihak selama dua tahun berturut-turut tanpa alasan, karena suami melanggar taktik talak karena adanya peralihan agama.

Kasus-kasus perceraian bisa diantisipasi dan dicarikan solusi salah satunya dengan cara memperdalam ilmu keluarga dan mempraktekan teori tersebut, mengikuti kegiatan sekolah pranikah dan pasca menikah semisal yang ada di Indonesia memajukan keluarga sakinah, hal ini dapat dijumpai melalui program atau kegiatan lembaga yang lebih signifikan, salah satunya Kelas Jodoh yang dikelola langsung oleh Ustadz Setia Furqon Kholid sebagai solusi untuk membina keluarga sakinah mulai dari pra-nikah hingga mentoring pasca menikah dari segi persiapan, finansial, ilmu, spiritual, emosional, dll. Kehebatan pola komunikasi dakwah yang diterapkan oleh Ustadz Setia Furqon Kholid sejauh ini telah mencakup member Kelas Jodoh 27.000 lebih peserta baik di Indonesia maupun Internasional.

Kelas Jodoh merupakan program yang mendukung pembentukan keluarga sakinah dengan dua cara yaitu secara online menggunakan fitur aplikasi Kelas Jodoh Mobile Apps yang bertujuan untuk membantu orang-orang yang masih single dan siap menikah untuk memantaskan diri dengan melalukan serangkaian tahapan yang ditentukan oleh program Kelas Jodoh. Fitur yang digunakan dalam Kelas Jodoh Ustadz Seia Furqon Kholid meliputi tes kepribadian, materi pemantasan diri, navigasi jodoh, dsb. Kemudian dengan cara offline atau tatap muka mengadakan seminar, acara sosial, dsb.

Dari permasalahan diatas, maka peneliti ingin mengkaji secara lebih mendalam tentang komunikasi dakwah yang disampaikan oleh Ustadz Setia Furqon Kholid melalui program Kelas Jodoh dalam merubah wawasan keluarga sakinah member Kelas Jodoh sejauh mana pengaruh komunikasi dakwah tersebut.

Oleh karenanya maka peneliti mengambil judul "Efektivitas Komunikasi Dakwah Kelas Jodoh Terhadap Perubahan Wawasan Member Kelas Jodoh untuk Membangun Keluarga Sakinah di Bandung".

\section{Tujuan Penelitian}

1. Untuk mengetahui program yang dilakukan dalam kelas jodoh.

2. Untuk memahami metode komunikasi dakwah pada kegiatan kelas jodoh yang dilakukan oleh ustadz Furqon Setia Khalid.

3. Untuk mengetahui sejauh mana efektivitas komunikasi dakwah kelas jodoh terhadap wawasan member kelas jodoh membangun keluarga sakinah.

\section{B. Metodologi Penelitian}

Jenis penelitian ini adalah peneltian kuantitatif deskriptif. Prosedur pemecahan masalah pada metode ini adalah dengan cara menggambarkan objek penelitian pada saat keadaan sekarang berdasarkan fakta-fakta sebagaimana adanya, kemudian dianalisis dan diinterpretasikan, bentuknya berupa survei dan studi perkembangan. Penelitian kuantitatif yang diukur melalui pengukuran data perhitungan ilmiah berasal dari member Kelas Jodoh di Bandung 76 orang dari populasi perhitungan sampel. Hasil dari penjumlahan statistik menyatakan bahwa $73 \%$ adanya Kelas Jodoh berpengaruh untuk mengubah wawasan member Kelas Jodoh dalam membangun keluarga sakinah. Adapun penelitian ini bersandarkan atas teori sebagai berikut: 


\section{Efektivitas}

Efektivitas ialah suatu keadaan yang menunjukkan tingkat keberhasilan atau pencapaian suatu tujuan yang diukur dengan kualitas, kuantitas dan waktu sesuai dengan yang telah direncanakan sebelumnya. Efektivitas adalah suatu tingkat keberhasilan yang dihasilkan oleh seseorang atau organisasi dengan cara tertentu sesuai dengan tujuan yang hendak dicapai. Dengan kata lain, semakin banyak rencana yang berhasil dicapai maka suatu kegiatan dianggap semakin efektif.

\section{Komunikasi Dakwah}

Komunikasi menjadi kebutuhan untuk mempertahankan keberlangusngan hidup manusia dalam lingkup masyarakat sebab berfungsi menyampaikan pesan yang ingin disampikan dan terjadi interaksi.bahan proses komunikasi akan dilakukan oleh manusia hingga akhir hayatnya baik melalui pesan terakhir sebelum menghembuskan nafas terakhir, gerak bahasa saat sakaratul maut atau dengan berupa wasiat.

Secara garis besar komunikasi adalah suatu proses ketika seseorang atau beberapa orang, keluarga, masyarakat, menciptakan dan menggunakan pesan informasi agar terhubung dengan kedua belah pihak.

Komunikasi dalam hal ini dapat diartikan sebagai proses sharing (berbagi) diantara pihak-pihak yang melakukan aktivitas komunikasi. Definisi tersebut memberikan beberapa pengertian pokok, yaitu komunikasi adalah suatu proses mengenai pembentukan, penyampaian, penerimaan dan pengolahan pesan.

Komunikasi dalam peran dakwah Islam sangat penting karena komuniksi dapat menciptakan iklim perubahan dengan memasukkan nilai-nilai persuasif Islam, sikap mental Islam, dan bentuk perilaku Islam semisal komunikasi dakwah yang diberlakukan untuk membangun keluarga yang sakinah.

Komunikasi dapat meningkatkan apresisi yang merupakan perangsang untuk bertindak secara riil; komunikasi dapat membantu masyarakat menemukan Islam dan pengetahuan Islam dalam mengatasi perubahan; komunikasi dapat membuat orang lebih condong untuk berpartisipasi dalam membuat keputusan di tengah kehidupan masyarakat; komunikasi dapat mengubah struktur kekuasaan masyarakat pada masyarakat yang awam ke masyarakat yang memiliki pengetahuan dan wawasan. Dengan kata lain, komunikasi juga dapat menciptakan umat menjadi loyal terhadap Islam; komunikasi memudahkan perencanaan dan implementasi program dan strategi dakwah; dan komunikasi dapat membuat dakwah menjadi proses yang berlangsung secara mandiri (self perpetuating). Dakwah berartikan memanggil, mengundang, mengajak, menyeru, mendiring. Mengajak, meyeru manusia kepada agama Islam sebagai pedoman hidup yang di ridhoi Allah dalam bentuk amar ma'ruf nahyi munkar dan amal sholeh dengan cara lisan maupun perbuatan, guna mencapai kebahagiaan hidup dunia dan akhirat.

Komunikasi harus disampaikan dengan baik dan benar agar isi pesan dapat diterima dengan baik pula. Hal ini dijelaskan dalam berdakwah mempunyai tata cara, etika, ataupun disebut sebagai prinsip komunikasi Islam agar komunikasi dakwah tersebut dapat berjalan dengan baik dan efektif. Dalam Al-Qur'an, prinsip komunikasi Islam dalam berdakwah ada enam, yaitu: Qaulan Sadida (berkata baik, benar, jujur tidak bohong), Qaulan Baligha (berkata tepat, lugas, fasih), Qaulan Ma'rufa (berkata yang pantas), Qaulan Karima (berkata yang mulia), Qaulan Layinan (berkata lemah dan lembut) dan Qaulan Maysura (berkata yang mudah untuk dipahami).

\section{Keluarga Sakinah}

Keluarga merupakan unit terkecil dalam upaya membentuk masyarakat yang berakhlaq dan berperadaban sesuai ketentuan Allah SWT. Karena itu perlu mengetahui secara jelas langkahlangkah konkret yang dapat mengantarkan ikatan perkawinan berjalan islami dan penuh kebahagiaan. Cara yang paling tepat untuk melestarikan perkawinan yang membawa suasana penuh kasih sayang dan kecintaan adalah dengan mengikuti petunjuk Allah yang dipraktekkan oleh Rasulullah SAW. 
Dalam Islam, keluarga tidak lepas dari kalimat sakinah, mawaddah wa rahmah bermakna satu keluarga dalam kehidupan rumah tangganya merasakan tentram, rukun dan serta mampu memenuhi kebutuhannya secara layak dan seimbang di dunia maupun di akhirat. Keluarga sakinah bersandarkan pada QS. Ar-Rum ayat 21:

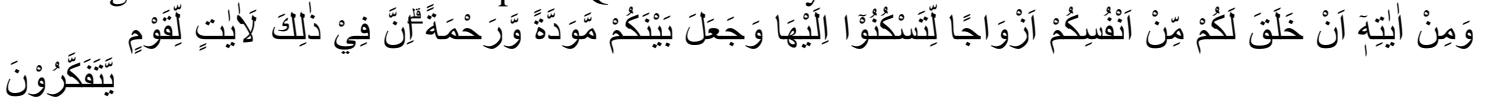

"Dan di antara tanda-tanda (kebesaran)-Nya ialah Dia menciptakan pasanganpasangan untukmu dari jenismu sendiri, agar kamu cenderung dan merasa tenteram kepadanya, dan Dia menjadikan di antaramu rasa kasih dan sayang. Sungguh, pada yang demikian itu benar-benar terdapat tanda-tanda (kebesaran Allah) bagi kaum yang berpikir."

4. Menurut KH. Zainuddin Ma'shum Ali kata sakinah memiliki 4 arti (berdasarkan pengolahan kata bahasa Arab yang tertera pada ayat diatas) yaitu: menenteramkan hati, ridho, menjadi tempat singgah baik secara zahir maupun bathin, dan saling ketergantungan atau membutuhkan antara pasangan suami dan istri. Komunikasi dalam keluarga setidaknya terdiri dari:

1. Komunikasi antara suami dan istri: Bagian terpenting dalam sebuah keluarga apabila komunikasi keduanya baik makan akan tercipta interaksi positif antar keduanya dan anggota keluarga lain.

2. Komunikasi antara orang tua dan anak: orang tua yang memiliki komunikasi yang baik dengan anaknya akan mengantarkan anaknya tumbuh sebagai pribadi yang baik dan jauh dari hal-hal negatif.

3. Komunikasi antara saudara: Komunikasi yang baik di antara saudara akan mendukung keutuhan sebuah keluarga. Oleh karenanya Islam sangat mendorong umatnya untuk menjalin tali silaturahim, Rasulullah SAW bersabda: "Barang siapa yang senang dilapangkan rizkinya, dipanjangkan usianya, maka hendaklah ia bersilaturahmi" (Riwayat al-Bukhari dari Anas).

\section{Pembahasan dan Diskusi}

\section{Kelas Jodoh}

Kelas Jodoh merupakan program kegiatan kelas pra-nikah hingga memberikan solusi untuk membangun keluarga yang sakinah sesuai syariat Islam. Dimulai dari yang berstatus single yang ingin menikah dengan persiapan, mulai dari mempersiapkan ilmu pernikahan, finansial, spiritual, emosional, dll.

Kelas Jodoh juga menjadi prasarana solusi untuk orang-orang yang mengalami kasus perceraian dan telah menangani orang yang berstatus janda maupun duda. Sebab orang yang telah mengalami kegagalan dalam pernikahan, kalau tidak belajar kembali ilmu pra-nikah akan mengalami hal yang sama. Disamping pernikahan membicarakan jodoh yang terpenting dari sebuah pernikahan yaitu apakah mengerti masalah-masalah di dalam rumah tangga, bagaimana menghadapi konflik, menurunkan ego, bagaimana belajar untuk menerima kekurangan pasangan yang akan diajarkan di Kelas Jodoh. Sehingga walaupun sudah menikah, akan menghindari untuk melakukan hal yang sama (permisalan ini berdasarkan banyaknya testimoni member Kelas Jodoh setelah mempelajari ilmu pernikahan dan menyadari kesalahan yang telah diperbuat. Misalnya: setelah menikah seorang istri harus patuh kepada suami bukan patuh pada orang tuanya lagi).

Bentuk kegiatan Kelas Jodoh terdiri dari offline: Meet \& Greet, Kelas Jodoh Roadshow, Kelas Jodoh Wilayah. Secara online: menggunakan mediasi sosial media melalui grup WhatsApp, website Kelasjodohapp.com, akun Instagram @ kelasjodohsfk dan aplikasi Kelas Jodoh yang bisa digunakan pengguna smartphone via android. Sistem pembelajarannya dilakukan belajar selama kurang lebih 15 hari, via grup WhatsApp dan website Kelas. Member Kelas Jodoh diberikan beberapa tugas yang harus dikerjakan, salah satunya membuat CV (curiculum vitae) ta'aruf. 
Adapun fasilitas kelas online yaitu:

1. Akses membership, 70 materi pra nikah berupa video dan e-book, diajarkan membuat $\mathrm{CV}$ ta'aruf, akses navigasi jodoh bagi yang siap menikah dan selesai tugas, grup WhatsApp terpisah ikhwan dan akhwat, dibimbing langsung founder Kelas Jodoh Ustadz Setia Furqon Kholid

2. Kelas Jodoh Mobile Apps akan membantu mengarahkan pembelajaran sebagai tahap persiapan mulai dari segi spiritual, emotional, true financial, intellectual, sampai action power. Fitur yang digunakan dalam Kelas Jodoh ustadz Setia Furqon Kholid meliputi tes kepribadian, materi pemantasan diri, navigasi jodoh, dan chat konsultasi . Guna rangkaian fitur yang disediakan untuk mempermudah dan melancarkan kegiatan Kelas Jodoh antar pemateri dan member agar pembelajaran lebih kondusif dan eksklusif.

3. Tes kepribadian (Setia Personality Test) dengan tes psikologi kontemporer yang dikembangkan Setia Furqon Kholid dan tim Kelas Jodoh . Gunanya agar para member lebih mengenal dirinya dan lebih percaya diri untuk menikah.

4. Materi pemantasan diri (selama 30 hari) dengan kurikulum pemantasan diri yang terstruktur dari mulai $30 \neg$ e-book selama 30 hari juga 40 video yang harus ditonton, tugas harian dan mingguan yang harus dikerjakan, dituntun untuk bisa memantaskan diri mendapatkan jodoh terbaik.

5. Navigasi jodoh, fitur ini bagi yang sudah selesai memantaskan diri selama 30 hari dengan e-book dan video berikhtiar menjemput jodoh dengan melihat member terdekat yang ada di area sekitar dan melakukan ta'aruf.

6. Chat konsultasi, dengan fitur ini konsultasi dengan tim kelas jodoh yang siap membantu menjawab pertanyaan member mulai dari pukul 09.00-16.00 WIB.

\section{Komunikasi Dakwah Ustadz Setia Furqon Kholid Melalui Kelas Jodoh}

Pola dakwah Ustadz Setia Furqon Kholid mencakup seluruh bentuk kegiatan dakwah. Seperti diantaranya dakwah bil lisan maupun bil haal dan menerapkan ilmu syariat khususnya tentang pernikahan dengan tindakan aksi nyata. Mulai dari menyiarkan ilmu pernikahan secara dakwah lisan melalui seminar-seminar, event, sampai wadah kegiatan kelas yaitu Kelas Jodoh untuk menjadi solusi para jomblo atau single untuk menemukan jodohnya. Menurut Ustadz Setia Furqon Kholid dakwah tidak hanya sebatas memotivasi belaka ilmu tentang pra-nikah tetapi harus ada solusi ta'arufnya. Dan begitu pula tidak bisa hanya memberikan jodoh tanpa ilmu. Sehingga keselarasan visi dan misi Kelas Jodoh sekaligus wadah untuk mendapat jodoh secara Islami.

Dakwah Ustadz Setia Furqon Kholid berasaskan ilmu syari'at. Mengumpulkan banyak refrensi-refrensi baik dari buku terkait ilmu pra-nikah, hadits-hadits yang tertera bagaimana Nabi SAW melakukan ta'aruf, malam pertama, bagaimana konsep Islam mengajarkan, dan juga menyederhanakan salafussholiat (manhaj atau metode dalam menjaga keteraturan dan kerapian sebuah ilmu, di samping mengatur pikiran manusia dan pekerjaan akal dengan kaidah-kaidah yang tetap).

\section{Efektivitas Komunikasi Dakwah Kelas Jodoh Terhadap Perubahan Wawasan Member Kelas Jodoh untuk Membangun Keluarga Sakinah di Bandung}

Suatu efektivitas dapat dikatakan berpengaruh jika adanya pernyataan yang konkrit berdasarkan data jelas sebagaimana peneliti menggunakan metode kuantitatif deskriptif. Uji instrumen melalui uji validitas, uji normalitas, uji reliabilitas, dan uji koefisien determinasi sebagai berikut:

1. Uji Validitas

(output tabel pearson correlation) dapat disimpulkan bahwa semua item kuesioner valid. Hal tersebut karena Score Correlation lebih besar dari $r$ table = 0,220. dengan demikian item kuesioner yang valid tersebut akan digunakan dalam analisis-analisis sebelumnya

2. Uji Reliabilitas

Berdasarkan hasil uji reliabilitas diatas dapat diketahui bahwa masing-masing variabel memiliki coarchbach alpha lebih besar dari 0.60 dengan demikian seluruh variabel yang digunakan dalam penelitian ini dikatakan reliabel. 
3. Uji Normalitas

Apabila nilai sig. $<0,05$ atau $5 \%$ maka variabel tersebut dinyatakan signifikan berpengaruh terhadap variabel dependen. Kegiatan Kelas Jodoh mempunyai nilai signifikasi sebesar $0,810>\alpha=5 \%=0,005$. Hasil ini berati bahwa kegiatan Kelas Jodoh berpengaruh positif signifikan terhadap perubahan wawasan member Kelas Jodoh dalam membangun keluarga sakinah

4. Uji Koefisien Determinasi

Koefisien determinasi dapat dilihat dari nilai R-Square (R2). Nilai ini menunjukkan kebaikan model, semakin besar R2 semakin baik modelnya. Nilai R2 berada antara 0\% sampai $100 \%$. Output di atas menunjukkan bahwa R2 yang diperoleh adalah 0,730 atau sebesar $0,730 \%$. Dari r-square tersebut dapat dimaknai bahwa setiap perubahan variabel wawasan member Kelas Jodoh (variabel Y) dapat dipengaruhi oleh variabel kegiatan kelas Jodoh (variabel X) sebesar 0,730\%

Berdasarkan pengisian data pada kuesioner yang peneliti berikan kepada member Kelas Jodoh yang berjumlah 76 orang mengenai perubahan wawasan member Kelas Jodoh untuk membangun keluarga sakinah maka peneliti menghitung hasil kegiatan Kelas Jodoh melalui software microsoft excel \& SSPS, maka didapatkanlah hasil nilai sebesar $0,730 \%$.

\section{Kesimpulan}

Berdasarkan hasil penelitian yang telah dilakukan peneliti untuk membahas mengenai efektivitas komunikasi dakwah Kelas Jodoh terhadap perubahan wawasan member Kelas Jodoh untuk membangun keluarga sakinah di Bandung, maka ditarik kesimpulan sebagai berikut:

Pertama, program yang dilaksanakan dalam Kelas Jodoh terdiri dari dua kegiatan yaitu secara online dan offline (tatap muka langsung). Secara offline, adanya kegiatan meet $\&$ greet (event seluruh alumni di Indonesia berkumpul di satu kota), Kelas Jodoh Roadshow (event seminar, nonton bersama film Sakura yang terpilih, silaturahmi dan ta'aruf) diadakan di kotakota yang memenuhi kuota untuk diadakan event tersebut. Kelas Jodoh wilayah (event yang diadakan pengurus wilayah dan biasanya event ini tidak berbayar, dan event ini difokuskan untuk member-member diwilayah masing-masing, bisa event sosial dan lainnya).

Kelas Jodoh sistem online, menggunakan mediasi sosial media melalui grup WhatsApp, website Kelasjodohapp.com, akun Instagram @kelasjodohsfk dan aplikasi Kelas Jodoh yang bisa digunakan pengguna smartphone via android. Kemudian Member Kelas Jodoh diberikan beberapa tugas yang harus dikerjakan, salah satunya membuat CV (curiculum vitae) ta'aruf. Adapun fasilitas kelas online yaitu: akses membership, 70 materi pra nikah berupa video dan ebook, diajarkan membuat CV ta'aruf, akses navigasi jodoh bagi yang siap menikah dan selesai tugas, grup WhatsApp terpisah ikhwan dan akhwat, dibimbing langsung founder Kelas Jodoh Ustadz Setia Furqon Kholid. Sistem pembelajaran kelas ini berlangsung kurang lebih 15 hari.

Kedua, komunikasi dakwah pada kegiatan Kelas Jodoh yang dilakukan oleh Ustadz Setia Furqon Kholid yaitu mencakup seluruh bentuk kegiatan dakwah. Seperti diantaranya dakwah bil lisan maupun bil haal dan menerapkan ilmu syariat khususnya tentang pernikahan dengan tindakan aksi nyata. Mulai dari menyiarkan ilmu pernikahan secara dakwah lisan melalui seminar-seminar, event, sampai wadah kegiatan kelas yaitu Kelas Jodoh untuk menjadi solusi para jomblo atau single untuk menemukan jodohnya.

Dakwah Ustadz Setia Furqon Kholid berasaskan ilmu syari'at. Mengumpulkan banyak refrensi-refrensi baik dari buku terkait ilmu pra-nikah, hadits-hadits yang tertera bagaimana Nabi SAW melakukan ta'aruf, malam pertama, bagaimana konsep Islam mengajarkan, dan juga menyederhanakan salafussholiat (manhaj atau metode dalam menjaga keteraturan dan kerapian sebuah ilmu, di samping mengatur pikiran manusia dan pekerjaan akal dengan kaidah-kaidah yang tetap). 
Ketiga, efektivitas komunikasi dakwah Kelas Jodoh terhadap wawasan member Kelas Jodoh dalam membangun keluarga sakinah adalah dari hasil penelitian yang telah dilaksanakan variabel X (Kegiatan Kelas Jodoh) berpengaruh terhadap variabel Y yakni perubahan wawasan untuk membangun keluarga sakinah member Kelas Jodoh di Bandung dari hasil perhitungan koefisien determinasi dengan nilai $73,0 \%$ yang berati sangat baik dan dengan adanya program Kelas Jodoh sangat berefek untuk mengetahui wawasan ilmu pernikahan.

\section{Acknowledge}

Alhamdulillah, atas segala kekuasaan Allah ta'ala tempat bergantung dan tanpa-Nya penulis bukan siapa-siapa. Allah Maha Pengasih dan Penyayang, memberikan kesempatan bagi penulis untuk menjadi salah satu seorang hamba yang berkualitas dengan menuntut ilmu dan merantau di tanah sunda hingga mencapai pendidikan sejauh ini di strata-1 (S1) pada Program Studi Komunikasi dan Penyiaran Islam Fakultas Dakwah Universitas Islam Bandung. Pada jenjang akhir pendidikan sarjana, penulis mempersembahkan penelitian dan mengiktui SPeSIA dengan judul "Efektivitas Komunikasi Dakwah Kelas Jodoh Terhadap Perubahan Wawasan Member Kelas Jodoh untuk Membangun Keluarga Sakinah di Bandung".

Pembuatan karya peneltian tentu bukan hal yang sangat mudah. Namun faktor dukungan dan positif vibes dari berbagai pihak penelitian ini dapat terselesaikan. Pada kesempatan kali ini penulis ingin hatur rasa hormat dan ucapan terimakasih yang setulus-tulusnya kepada semua pihak yang telah membantu dalam proses menyelesaikan penelitian ini. Terutama untuk kedua orang tua peneliti mama Sakinah Ghonim dan Abah Hamdan Basulthanah yang mengiringi do'a disetiap langkah penelti, saudara, keluarga dan kerabat, seluruh civitas akademik Fakultas Dakwah Unisba dan Unisba. Tak lupa untuk dosen pembimbing yang begitu sabar mengarahkan pengetahuan peneliti sampai bisa mengikuti proses SPeSIA, ibu Dr. Hj. Nia Kurniati Syam, Dra., M. Si selaku pembimbing satu dan ibu N Sausan m Shaleh, Lc., MA selaku pembimbing dua dalam penelitian.

Semoga adanya penelitian ini dapat membantu bertambahnya wawasan, menjadi refrensi dari setiap penelitian sesuai objek yang berlaku dan dapat bermanfaat untuk seluruh pembaca. Aamiin.

\section{Daftar Pustaka}

\section{Buku:}

[1] Badan Litbang Dan Diklat Kementerian Agama Ri. Komunikasi Dan Informasi. Jakarta: Lajnah Pentashihan Mushaf Al-Qur'an, 2011.

[2] Drs. Muhammad Thalib. 40 Langkah Melestarikan Kemesraan Suami Istri. Bandung: Irsyad Baitus Salam, 1997.

[3] Fethullah Gulen. Dakwah. Jakarta Selatan: Republika Penerbit, 2011. Halaman 26

[4] Jalaluddin Rakhmat. Catatan Kang Jalal. Bandung: Remaja Rosdakarya,1998 Halaman 78-79

[5] K. H. Muhammad Arifin Ilham. Menggapai Keluarga Sakinah. Jakarta Timur: Zikrul Hakim, 2013.

[6] Ira Puspitorini. Stop Perceraian Selamatkan Perkawinan. Jawa Tengah: Desa Pustaka Indonesia, 2019.

[7] Ir. Syofian Siregar, M. M. Metode Penelitian Kuantitatif. Jakarta: Prenadamedia Group, 2013.

[8] Thoha Husein. Al-Qur'an Dan Terjemahannya. Jakarta: Cv. Darus Sunnah, Halaman 407 Jurnal:

[1] Konita Astriani, Rachmat Effendi, Hendi Suhendi, "Efektivitas Pengajian Sabtu dalam Pembinaan Keberagamaan Jamaah di Masjid Al-Ukhuwwah Kota Bandung" dalam Prosiding Komunikasi Penyiaran Islam, No.2, Vol.4, Tahun 2018.

\section{Internet:}

[1] https://Www.Dosenpendidikan.Co.Id/Efektivitas-Adalah/ Diunduh 8/6/2021 Pukul 19.07 WIB 